\title{
O DELÍRIO COMO REESTRUTURAÇÃO DO SUJEITO PSICÓTICO ${ }^{1}$
}

\author{
Nathália Gomes Duarte², Centro Universitário Santo Agostinho
}

\section{RESUMO}

O referido estudo trata-se de um relato de experiência de Estágio Curricular Obrigatório desenvolvido em um Centro de Assistência Psicossocial (CAPS) da cidade de Teresina-Piauí, sob o olhar psicanalítico de uma das estagiárias. Os objetivos desse trabalho são discorrer sobre a necessidade da compreensão do psicótico como sujeito digno de voz e de existência e promover discussões acerca da loucura e das formas de entendê-la a partir do enfoque psicanalítico. Os instrumentos e ações utilizadas foram observação participante da rotina dos usuários, inserção em projetos já efetivados pela instituição, elaboração de atividades com pinturas, desenhos, música e dança, grupos de vivência com roda de conversa acerca de temas específicos e visita domiciliar. A partir dos resultados obtidos, por meio da execução de tais tarefas, percebeu-se a necessidade da compreensão dos usuários como detentores de voz, além da inevitabilidade da escuta e da legitimação dos delírios que se apresentavam durante os dias de estágio. Dessa forma, o referido estudo propõe apresentar um breve relato da constituição histórica da psicose na psicanálise de Freud e Lacan, como suporte teórico, além da exposição das estratégias e dificuldades alcançadas pela estagiária sob uma perspectiva psicanalítica. Por fim, a pesquisa se valida da efetivação da aplicação do método psicanalítico nos dispositivos de saúde mental, utilizando como técnica o que sempre coube ao saber psicanalítico, a escuta e o não silenciamento do sofrimento e da dor. Uma vez que estes, como delírios e alucinações são, na verdade, uma tentativa de reestruturação do psicótico no meio simbólico.

Palavras-Chave: Psicanálise. Psicose. CAPS. Saúde Mental.

\section{ABSTRACT}

\section{INTRODUÇÃO}

O referido estudo trata-se de um relato de experiência de estágio Curricular Obrigatório desenvolvido em um Centro de Assistência Psicossocial (CAPS) da cidade de Teresina-PI, sob o olhar psicanalítico de uma das estagiárias. O estágio foi oriundo da disciplina de Psicologia e Saúde Pública do sétimo período do curso de Psicologia do Centro Universitário Santo Agostinho

\footnotetext{
${ }^{1}$ Trabalho apresentado no Congresso Brasileiro Ciência e Sociedade (CBCS 2019), promovido pelo Centro Universitário Santo Agostinho, de 03 a 05 de outubro de 2019, em Teresina-PI.

${ }^{2}$ Relação de autores, com as seguintes informações: titulação máxima, identificação do curso e/ou nome da instituição a que está vinculado, E-mail. 
(UNIFSA).

Durante a realização do estágio nos meses de Novembro e Dezembro de 2019, a instituição contava com 2.500 prontuários, onde 1.750 usuários frequentavam efetivamente o serviço e em média 50 usuários passavam o turno matutino no CAPS, enquanto 17 a 20 usuários passavam o dia todo no centro, pois, segundo os servidores, estes contavam com transtornos graves e persistentes. A equipe multidisciplinar vigente contava com 4 psicólogas, 4 assistentes sociais (2 por turno), 4 psiquiatras, 1 nutricionista, 4 enfermeiras e 4 técnicas de enfermagem.

Segundo o Manual de Saúde Mental no SUS (2004), os CAPS são instituições carregadas de oferecer atendimento multiprofissional à população de sua área de abrangência, de forma a acolher e integrar os pacientes com transtornos mentais, estimular sua integração social e incentivar a autonomia. Uma de suas características principais é "buscar integrá-los a um ambiente social e cultural concreto, designado como seu "território", o espaço da cidade onde se desenvolve a vida quotidiana de usuários e familiares". (MANUAL DE SAÚDE MENTAL DO SUS, 2004, p.9).

Para subsidiar teoricamente as ações realizadas pela aluna, foi utilizado dos referenciais teóricos da Psicanálise, que de modo geral, concentra seus aportes teóricos acerca da psicose nas obras de Freud e Lacan. Dessa forma, nos primórdios da psicanálise, o tema da psicose foi tratado por Freud com base nos seus estudos clínicos acerca da neurose, com as nomeadas histéricas, estendendo-se a análise da autobiografia escrita pelo Presidente Schreber (Memórias de um doente de nervos), que findou no conhecido Caso Schreber, analisado por Freud em 1911, e desenrolar da formação de um sistema delirante caracterizado como estrutura psicótica. (COELHO DOS SANTOS \& OLIVEIRA, 2012).

Nesse sentido, o presente trabalho surge da necessidade de partilhamento das situações experienciadas pela aluna, onde a escuta e a validação dos discursos psicóticos foram o foco em sua intervenção. Para, além disso, a sua relevância reside na contribuição para a articulação dos trabalhos nas redes de saúde e o enfoque psicanalítico, desconstruindo a ideia de que o saber psicanalítico finda-se na clínica. Por fim, os objetivos desse trabalho são discorrer sobre a necessidade da compreensão do psicótico como sujeito digno de voz e de existência e promover discussões acerca da loucura e das formas de entendê-la a partir do enfoque psicanalítico.

\section{MATERIAL E MÉTODOS}


As ações do estágio curricular obrigatório aconteceram durante os meses de Novembro de 2018 a Dezembro de 2018 em 10 dias, sendo eles 19, 20, 21, 23, 26, 27, 28 e 30 de Novembro e 03 e 06 de Dezembro de 2018. Os instrumentos e ações utilizadas foram observação participante da rotina dos usuários, inserção em projetos já efetivados pela instituição, elaboração de atividades com pinturas, desenhos, música e dança, grupos de vivência com roda de conversa acerca de temas específicos, visita domiciliar e conversas com os colaboradores.

As intervenções ocorreram sobre a supervisão geral do Professor da disciplina e supervisão local de um profissional da psicologia, com uma equipe de quatro alunas de psicologia. É importante frisar que as discussões aqui descritas são fundamentadas no olhar de apenas uma dessas alunas que durante o processo entrelaçou-se com o enfoque psicanalítico.

\section{RESULTADOS E DISCUSSÃO}

As atividades foram realizadas em dias da semana aleatórios, no período matutino, geralmente das $8 \mathrm{~h}$ às $11 \mathrm{~h}$. Quanto à quantidade de usuários envolvidos durante as atividades em que a estagiária participou direta ou indiretamente tem-se um total de 181 usuários.

Inicialmente no dia 19 de Novembro realizou-se a inserção das alunas nas instalações do CAPS, houve o acolhimento por parte da equipe multidisciplinar, tal como a supervisora psicóloga. Após o acolhimento, a estagiária participou de um projeto já desenvolvido pela redutora de danos, onde os usuários confeccionaram mandalas que seriam utilizadas na festa do CAPS, o que permitia a promoção de autonomia e empoderamento acerca da produção de materiais. Nesse momento, a aluna iniciou uma longa conversa com um dos usuários que relatou todo o seu percurso pelo CAPS, além disso, permitiu a esse sujeito, por meio da escuta, a validação de seu discurso, que por muitas vezes, era desconsiderado pelos servidores.

Já no dia 20 de Novembro, a estagiária participou do Bazar organizado pelos usuários e coordenado pela terapeuta organizacional, a atividade contou com a presença de 7 usuárias. Posterior ao bazar, já nas comodidades do CAPS, a estagiária realizou, juntamente com outras três estagiárias, dinâmicas que permitissem a apresentação dos usuários e autorretrado por meio do desenho e pintura. Essas atividades permitiram a expressão e estabelecimento de vínculos dos usuários, além disso, possibilitou, mais uma vez, a escuta.

No terceiro dia, dia 23 de novembro, a estagiária participou do Fórum entre RIA's (Rede, DOI: $10.17648 / \mathrm{cbcs}-2019-110633$ 
Instituições e Articulações). Durante o evento houve apresentação cultural de usuários do CAPS infantil, apresentação das RIA's de cada zona de Teresina, além de rodas de conversa. É importante salientar a importância das RIA's para a articulação entre redes, uma vez que esta apresenta como objetivos a desospitalização, desinstitucionalização, intersetorialidade e apropriação do território com a inserção do usuário neste.

Na sexta feira, dia 23 de Novembro, a estagiária, juntamente com uma enfermeira e outra estagiária de psicologia, participou de duas visitas domiciliares. As visitas ocorreram com usuários que possuíam dificuldades ou limitações físicas para irem até o CAPS. A primeira visita aconteceu na residência de um usuário que sofre de esquizofrenia, a enfermeira coletou sangue e nos contou sobre seu histórico adoecedor. A segunda visita foi a um paciente que vive em cárcere privado, o paciente que nomearei de José vive com sua mãe, que nomearei de Maria. Durante a visita, Dona Maria queixou-se sobre os gastos financeiros e psicológicos que estava tendo com o filho, além de comportamentos agressivos do filho, porém, afirmou que este não estava tomando as medicações corretamente. Quando questionada sobre o filho, Dona Maria utilizou dessas queixas para justificar o aprisionamento do filho em um pequeno quarto. O quarto onde José vivia contava com um banheiro, uma cama, uma rede e uma abertura com grades por onde a mãe o alimentava. Durante a visita, a estagiária tentou iniciar uma conversa com o morador, porém, este não apresentava fala, apenas balbucios. A mãe apresentou algumas falas que obtiveram a atenção da estagiária. "Ele começou a bagunçar a casa e incomodar os vizinhos foi por isso que tranquei ele no quarto [...], olha, minha fia, aqui do lado também tem um que ficou louco e tá preso no quarto".

Já no dia 26 de Novembro, a estagiária, juntamente com a assistente social e mais 3 estagiárias de psicologia, inseriu-se no grupo de final de semana, já vigente da instituição, onde os usuários relataram sobre o seu final de semana. Após o grupo, realizou-se uma roda de conversa sobre planos e metas para 2019 e momento de dança e música. As duas últimas ações permitiram aos usuários expressões corporais, além de percepção de futuro e escuta por parte da estagiária. No dia seguinte, dia 27, realizou-se grupo de vivências com palavras significativas aos usuários que eram explicadas e direcionadas a algum colega. O momento permitiu o fortalecimento de vínculos e escuta.

Dia 28 de Novembro, já no sétimo dia de estágio, realizou-se um evento em outro local, que contou com a colaboração dos usuários para a sua organização. Durante a execução do evento, a estagiária pôde oferecer momentos de escuta e obteve percepção dos usuários em 


\section{CONGQEESSOCIENCIAESOCIEDADE

ambientes que não fossem o CAPS. Além disso, o momento contou com a participação de profissionais da área.

No oitavo dia de estágio, dia 30, a estagiária participou da festa de aniversário do CAPS, um dos momentos mais ricos da experiência, uma vez que houve uma maior interação com os usuários e com seus familiares. O evento contou com a participação ativa dos usuários, que relataram em roda de conversa sobre o seu percurso nos ambientes manicomiais e assistência psicossocial, além disso, momentos de expressão por meio da dança e interação com malabaristas convidados.

Por fim, no penúltimo dia e último dia, 3 e 4 de Novembro, foram realizados, respectivamente, planejamento e despedida das estagiárias. O momento da despedida contou com a confecção de um varal, pinturas em papel $A 3$, danças e entrega de lembrancinhas confeccionadas pela estagiária e por outras três estagiárias de psicologia. As pinturas permitiam aos usuários a expressão de seus sonhos, após o momento da pintura, cada usuário, por meio da fala, explicava e nomeava seus desenhos e posteriormente, prendiam no varal.

\section{DISCUSSÃO}

Após a execução das atividades, percebeu-se a necessidade da compreensão dos usuários como detentores de voz, além da necessidade da escuta e validação dos delírios que se apresentavam durante os dias de estágio. Dessa forma, a seguir, a constituição histórica da psicose na psicanálise de Freud e Lacan, como suporte teórico, além das estratégias e dificuldades alcançadas pela estagiária.

Inicialmente, a diferença estrutural determinante entre as psicoses e as neuroses é formalizada nos artigos "Neurose e Psicose, onde Freud as distingue partindo do pressuposto que a Neurose é o resultado do conflito entre o Eu e o ID, não havendo ruptura total com o mundo externo, enquanto que na Psicose há uma perturbação nos lações entre o Eu e o Mundo Externo causando ruptura com a realidade no primeiro momento, e em um segundo momento há uma tentativa de reparação com a realidade, as alucinações e delírios. Dessa forma, o psicótico rompe totalmente com a realidade, predominando assim o isso, ou em outras palavras, o Inconsciente. (FREUD, 1923) 


\section{CONGBESSO CIENCIAESOCIEDADE

Freud (1923, p. 161) ainda afirma que "o delírio se encontra aplicado como um remendo no lugar em que originalmente uma fenda apareceu na relação do ego com o mundo externo". Assim, o delírio, preconizado pelo saber médico como fala desorganizada e ilógica, é na verdade uma tentativa de cura e reconstrução da realidade, formulada pela psicose. Enquanto que as alucinações, segundo Freud (1894) são "partes do conteúdo de suas experiências infantis recalcadas, ou seja, sintomas do retorno do recalcado"(p.179).

Dessa forma, durante todo o processo de estágio, utilizou-se da escuta dos delírios dos usuários, uma vez que esses dizem a respeito do sujeito em si, de como esse se reconstrói frente à psicose, conteúdos que os neuróticos escondem, além de apresentar-se como a forma do sujeito dizer sua verdade. Porém, ainda assim, essa verdade é recoberta dentro dos ambientes de assistência psicossocial, seja por meio do excesso de medicamentos utilizados, seja pelo silenciamento das vozes por ausência de escuta. Assim, Freud aponta:

Se essa precondição de um conflito com o mundo externo não nos é muito mais observável do que atualmente acontece, isso se deve ao fato de que, no quadro clínico da psicose, as manifestações do processo patogênico são amiúde recobertas por manifestações de uma tentativa de cura ou uma reconstrução. (FREUD, 1923, p. 161)

Ademais, o que se observou, de uma maneira mais restrita à atuação médica, foi o aniquilamento do sujeito em uma infinidade de sintomas e o descarte da subjetividade. Durante a atuação da estagiária, percebeu-se a concepção medica como primordial e final, uma vez que este atua na definição psicopatológica do sujeito, que é usada pelos usuários como nomeação de si mesmo. Percebeu-se o citado, na execução de uma atividade realizada, onde os sujeitos identificavam-se através de sua patologia. Dessa forma, não há conflito, nem desejo, nem sofrimento, apenas uma supressão disso tudo e o vazio que daí resulta.

Complementando as ideias freudianas, Lacan (1956) em seu Seminário 3 (As psicoses) contempla uma de suas principais teorias, a de que o desejo do sujeito é marcado por significantes e é por meio dos significantes introduzido pelo Outro que ele se coloca no mundo. Além disso, entre esses significantes, há sempre aqueles primordiais pra formação do sujeito, e é justamente na ausência de um desses que está a psicose, a ausência do Significante do Nome do Pai.

Dessa forma, Lacan ainda afirma que "para que haja realidade, acesso suficiente à realidade, para que o sentimento de realidade não seja como ela é na psicose, é preciso que o 


\section{CONGEESSO CIENCIAESOCIEDADE \\ Inovação, Diversiliaile e Sustentahilitidatle}

complexo de Édipo tenha sido vivido" (LACAN, 1956, p. 226). Assim a psicose caracteriza-se com a não completude dos três estágios denominados por Lacan, estando assim estagnado no primeiro tempo, ainda no registro do imaginário. Nesse primeiro tempo, a criança é o objeto de desejo da mãe, onde a mãe é portadora do falo para a criança e, por sua vez, esta é o falo da mãe. A relação é caracterizada por ausência de subjetividade da criança onde o desejo da criança é escravo do desejo da mãe.

Assim, nas elaborações apresentadas no "O Seminário, livro 3: as psicoses" (Lacan, 19551956/2008) e no "O Seminário 5: as formações do inconsciente" (Lacan, 1957-1958/1999), o autor destaca a função do pai , que já no segundo tempo, é a de intervir na relação imaginária da mãe com a criança, instaurando assim a lei e inserindo a criança ao registro simbólico. Porém, o que ocorre na psicose é justamente a foraclusão desse significante primordial, onde o Nome do pai é rejeitado, não inscrito, foracluído, tendo como consequência a ausência do mediador simbólico e da castração.

Dessa forma, para Lacan (1958/1998) para que ocorra a eclosão da psicose, é preciso que o Nome do Pai foracluído seja evocado a responder em uma estrutura dual e imaginária, onde a função simbólica encontra-se ausente. Mais uma vez nas obras lacanianas, há o retorno as ideias freudianas de que os delírios devem ser legitimados, que é a partir deles que o sujeito se vê um pouco estabilizado, pois tenta suprir a carência do significante Nome-do-pai, assim "um delírio deve ser julgado em primeiro lugar como um campo de significação que organizou um certo significante" (Lacan, 1955-1956/1992, p. 141) e que uma investigação da psicose tem como regra fundamental deixar o sujeito falar o maior tempo possível.

Retomando as práticas no campo de estágio, notou-se a complexidade de significados presentes nos delírios dos usuários que repetiam demasiadamente o mesmo discurso, que ao mesmo tempo em que os estabilizavam em um ambiente com regras, era silenciado pelos profissionais presentes. Dessa forma, percebeu-se, a partir da escuta desses significantes, a retomada a aspectos da infância dos usuários além da fantasia de si e dos outros.

Por fim, no início do estágio, questionamentos quanto à aplicação da psicanálise surgiram, se cabia o saber psicanalítico e sua prática em outros contextos que não a clínica. Porém, essa ideia foi desconstruída durante todo o processo, juntamente com o estudo teórico e a atuação prática com os usuários. Além disso, como resposta a tal questionamento Lacan (1966/1998) 


\section{CONGQEESSOCIENCIAESOCIEDADE \\ Inovação, Diversiliaile e Sustentalililitaile}

propõe o termo "método psicanalítico" para designar toda forma de prática analítica que seja executada em local que não seja o consultório clínico tradicional.

\section{CONSIDERAÇÕES FINAIS}

Com o fim das atividades realizadas durante os dias de estágio, ficou a efetivação da aplicação do método psicanalítico nas instituições públicas, utilizando como técnica o que sempre coube ao saber psicanalítico, a escuta. Além disso, a constituição histórica e teórica da psicose por meio dos estudos de Lacan e Freud permite o entendimento do caráter multidirecional da constituição da psicose.

Para, além disso, percebeu-se durante o decorrer do estágio a posição dos trabalhadores de sujeito do suposto saber nos significantes dos usuários, uma vez que estes sempre se dirigiram aos estagiários e trabalhadores efetivos como "doutores". A partir disso Alberti e Figuereido (2006) defendem que o sujeito imerso na instituição é sempre um sujeito institucionalizado, seja qual for o nível. Nesse sentido, o psicanalista também é um sujeito institucionalizado, porém, também é um sujeito que questiona o status vigente do "desde sempre isso foi assim".

Por fim, o uso do método psicanalítico nos dispositivos de saúde mental acredita e é ancorado pela não silenciamento do sofrimento e da dor, uma vez que estes, como delírios e alucinações são, na verdade, uma tentativa de reestruturação do psicótico no meio simbólico. Dessa forma, cabe aos trabalhadores dos dispositivos, a desconstrução do saber médico, positivista, estigmatizador e marginalizador , afim de promover a legitimação dos usuários.

\section{REFERÊNCIAS}

ALBERTI, S. \& FIGUEREIDO, A. C. Psicanálise e saúde mental: uma aposta. Rio de Janeiro, Companhia de Freud, p. 7-18, 2006.

Brasil. Ministério da Saúde. Saúde mental no SUS: os centros de atenção psicossocial. Brasília (DF); 2004.

Coelho dos Santos, T. \& Oliveira, F. L. G. Teoria e clínica psicanalítica da psicose em Freud e Lacan. Psicologia em Estudo, v.7, n.1, p. 73-82, 2012.

FREUD, S - As neuropsicoses de defesa - vol. III, Rio de Janeiro, Imago editora, 1894.

FREUD, S. Neurose e psicose, v. XIX, 1923. 


\section{cONGERESOC CIENCIAESOCIEDADE \\ $\rightarrow$ Inovação, Diversidlaile e Sustentahililitaile}

Lacan, J. (1999). O seminário. Livro 5. As formações do inconsciente. Rio de Janeiro: Jorge Zahar. (Trabalho original publicado em 1957-1958)

Lacan, J. (1992). O seminário. Livro 3: As psicoses. Rio de Janeiro: Jorge Zahar. (Trabalho original publicado em 1955-1956)

Lacan, J. (1998). De uma questão preliminar a todo tratamento possível da psicose. In J. Lacan, Escritos (pp. 573-590). Rio de Janeiro: Jorge Zahar. (Trabalho original publicado em 1958)

Lacan, J. (1998). Propos sur la causalité psychique. In J. Lacan, Écrits. (pp.151-193). Paris: Seuil. (Originalmente publicado em 1966) 